\title{
LITERASI MAKAN SEHAT DI SDN BOJONG NANGKA 01 BOGOR
}

\author{
${ }^{1 *}$ Nur Hasanah, ${ }^{2}$ Chairunnisa, ${ }^{3}$ Syamzah Ayuningrum \\ STKIP Kusumanegara, Jakarta, Indonesia \\ Email : ${ }^{*}$ ur.hasanahmnq@gmail.com
}

Manuskrip: Desember -2021; Ditinjau: Desember -2021; Diterima: Desember -2021;

Online: Januari-2022; Diterbitkan: Januari-2022

\begin{abstract}
ABSTRAK
Pengabdian kepada masyarakat dengan tema Literasi Makanan Sehat bertujuan untuk meningkatkan kewaspadaan para guru hingga siswanya agar memperhatikan tidak hanya kebersihan makanan tetapi juga nutrisi yang terdapat dalam makanan sehingga nantinya pertumbuhan dan perkembangan para siswa tidak bermasalah. Kegiatan ini disampaikan melalui metode ceramah, demonstrasi dan permainan yang dilaksanakan selama 2 hari. Hasil dalam pengabdian kepada masyarakat ini adalah peningkatan dan pemahaman guru dan siswa SDN Bojong Nangka 1 Bogor terhadap pentingnya makanan sehat di lingkungan sekolah.
\end{abstract}

\section{Kata Kunci: Makan Sehat}

\section{PENDAHULUAN}

Makanan sehat untuk anak-anak khususnya di Sekolah Dasar sudah lama menjadi perhatian. Terlebih saat ini, arus informasi sangat deras melalui jaringan internet. Beberapa kali media mengungkap berita bagaimana makanan tidak sehat berbahaya untuk anak-anak yang sangat menyukai aktifitas jajan. Jajanan yang tidak sehat, kotor, dan tidak dalam pantauan orang tua dan guru menjadi masalah baru. Dilansir dari Kompas.com, di Pacitan, wabah hepatitis A menyebar hingga memakan korban 1.102. Peristiwa yang sama juga pernah terjadi di awal tahun 2019 di sekolah dasar di kota Depok, Jawa Barat. Sebanyak 33 siswa menderita hepatitis A dan dinas kesehatan setempat menyatakan bahwa penyebab dari wabah hepatitis ini tidak lain adalah makanan yang tidak dijaga kebersihannya, Kementerian Kesehatan sudah mengeluarkan himbauan agar masyarakat melakukan upaya pencegahan dari menjaga kebersihan hingga melakukan vaksinasi. KLB tersebut berawal dari lalainya penjual makanan di kantin sekolah dalam menjaga kebersihan sehingga menyebabkan penyakit hepatitis A menjangkit para siswa di sana. Berkaca dari kasus ini, para orangtua dan guru sebaiknya mewaspadai kebiasaan anak-anak untuk memakan makanan yang tidak dapat dijamin kebersihannya. Belum lagi, aktifitas jajan di sekolah seringkali dikatakan tidak sehat karena makanan yang disajikan tidak memperhatikan nutrisi yang dikandung makanan tersebut. Nutrisi dalam makanan tentu saja berperan penting bagi pertumbuhan dan perkembangan anak-anak. The Australian National Health and Medical Research Council (2013) menyatakan bahwa nutrisi yang optimal penting untuk pertumbuhan dan 
perkembangan anak yang sehat. Makanan sehat berkontribusi dalam mecapai dan menjaga berat badan yang sehat dan memberikan perlindungan terhadap penyakit kronis dan kematian dini. Oleh karena itu, memberikan pengetahuan mengenai pentingnya makanan sehat baik untuk orangtua, guru, hingga anak-anak merupakan hal yang penting untuk dilakukan. Setelah memberikan pengetahuan tersebut, diharapkan semua pihak lebih memperhatikan makanan yang dikonsumsi setiap harinya demi menciptakan generasi muda yang sehat.

Semakin banyaknya ketidakwaspadaan terhadap makanan yang dikonsumsi oleh masyarakat terutama anak-anak menjadi perhatian bagi STKIP Kusuma Negara Jakarta khususnya program studi Pendidikan Guru Sekolah dasar. Oleh karena itu, tim pengabdian masyarakat dari prodi PGSD pun menyusun perencanaan dan pelaksanaan penyuluhan terhadap para guru dan siswa di SDN Bojong Nangka 01 Bogor. Penyuluhan ini diadakan dalam rangka meningkatkan kewaspadaan para guru hingga siswanya agar memperhatikan tidak hanya kebersihan makanan tetapi juga nutrisi yang terdapat dalam makanan sehingga nantinya pertumbuhan dan perkembangan para siswa tidak bermasalah.

\section{METODE}

Metode yang digunakan dalam pengabdian masyarakat Literasi Makanan Sehat ini adalah metode ceramah, demonstrasi dan permainan, adapun penjelasan metode sebagai berikut; Metode Ceramah dimana Tim Pengabdian Masyarakat Prodi PGSD yang terdiri dari beberapa dosen memberikan materi mengenai pentingnya memperhatikan dan menjaga kebersihan makanan hingga memperhatikan nutrisi yang terkadung dalam makanan yang dikonsumsi. Materi ini dijelaskan dengan menggunakan slide show. Sedangkan Metode Demonstrasi dilakukan dimana Guru dan siswa langsung diperkenalkan pada contoh makanan yang bernutrisi seperti nasi, sayur, ikan, hingga cemilan sehat untuk siswa seperti biscuit dan susu kemasan. Di saat yang sama, tim dibantu oleh mahasiswa membagikan cemilan sehat yang kaya nutrisi untuk langsung dikonsumsi oleh siswa. Salah satu aktifitas hidup sehat juga langsung dipraktekkan dalam penyuluhan ini yaitu senam pagi. Setelah senam pagi selesai dilaksanakan, tim pengabdian masyarakat menghimbau peserta untuk mencuci tangan dan mengkonsumsi makanan yang telah dibagikan. Dan, Metode Permainan dimana Salah satu karakter anak sekolah dasar adalah menyukai permainan. Gerakan fisik dianggap sebagai salah satu stimulasi untuk ketuntasan perkembangan motorik mereka. Oleh karena itu, tim pengabdian masyarakat mengajak siswa bermain sekaligus belajar pentingnya gaya hidup sehat yang melibatkan Gerakan fisik seperti olahraga. Kegiatan ini pun disambut antusias oleh siswa dan para guru.

\section{HASIL DAN PEMBAHASAN}

Karena kondisi ruangan yang terbatas, penyuluhan dilakukan 2 kali. Pada tanggal 14 Agustus 2019, tim pengabdian kepada masyarakat melakukan penyampaian materi tentang pentingnya makanan sehat dan bersih kepada para guru SDN Bojong Nangka 01 Bogor. 


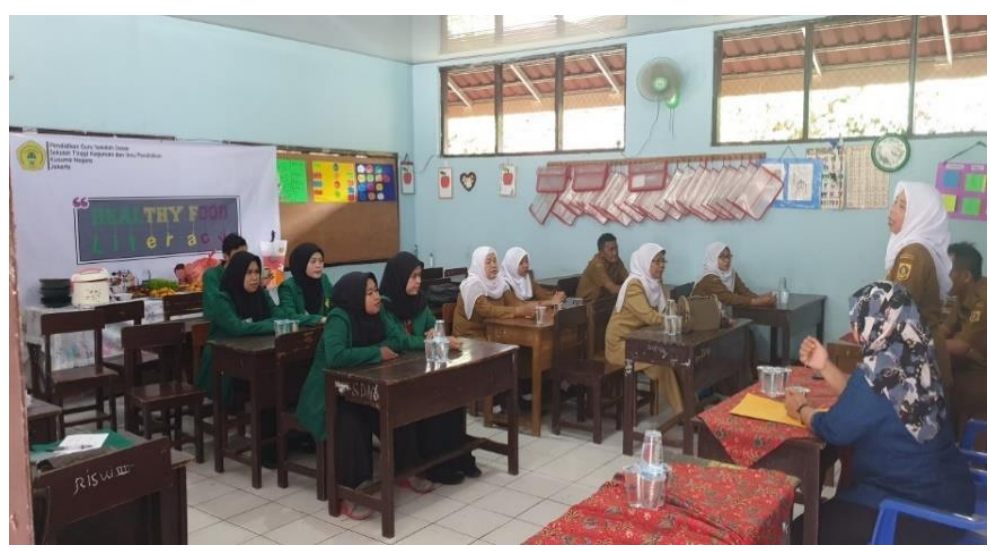

Gambar 1. Sesi pemaparan materi

Dalam penyuluhan para guru telah memahami bahaya yang tersembunyi jika membiarkan anak anak jajan yang tidak sehat hingga tidak terjamin kebersihannya. Makanan sehat telah dipahami oleh para guru sebagai makanan yang memiliki nutrisi untuk mendukung pertumbuhan dan perkembangan anak. Selain itu, nutrisi yang telah terkandung dalam makanan pun tetap harus terjaga kebersihan dan keamanannya mengingat Sebagian besar makanan yang ada saat ini melalui berbagai macam proses persiapan. Jika di sekolah, maka para guru dapat lebih waspada Ketika melihat para penjual makanan menyiapkan dan menyajikan makanan dengan cara yang kurang higienis. Selain itu, anak-anak pun diperkenalkan budaya mencuci tangan dengan baik dan benar. Hal ini tentunya untuk mendukung budaya sehat sebelum makan.

Para guru mengaku telah memberikan himbauan kepada siswa dan tentunya mereka berharap himbauan tersebut didukung juga oleh perilakua para wali murid atau orang tua. Selain itu, pihak sekolah juga memberikan himbauan yang sama untuk para pedagang secara lisan dan tidak resmi.

Pada tanggal 24 Agustus 2019, penyuluhan kembali diadakan. Mengingat ruangan yang tidak dapat menampung jumlah seluruh siswa SDN Bojong Nangka 01 Bogor, maka penyuluhan dilakukan di lapangan olahraga setelah kegiatan senam pagi bersama. Para siswa terlihat menyimak dengan baik dan menyambut dengan senang cemilan sehat yang dibagikan tim pengabdian masyarakat. Sebagian besar siswa menyukai susu yang menjadi salah satu makanan sehat yang paling mudah ditemukan dan cukup terjangkau saat ini.

Tim pengabdian PGSD STKIP Kusuma Negara juga mengajak siswa dan guru duduk membentuk lingkaran dan memperkenalkan beberapa macam permainan yang dapat dijadikan stimulasi motorik siswa yang tentunya penting untuk mendukung perkembangan dan pertumbuhan mereka. Dalam sesi ini, siswa sangat antusias melakukan kegiatan bermain. Para guru pun memahami bahwa bermain tidak semata-mata bermain saja. Dalam permainan pun, guru dapat membangun daya konsentrasi anak dan hal ini nantinya akan mendukung pembelajaran para siswa. 


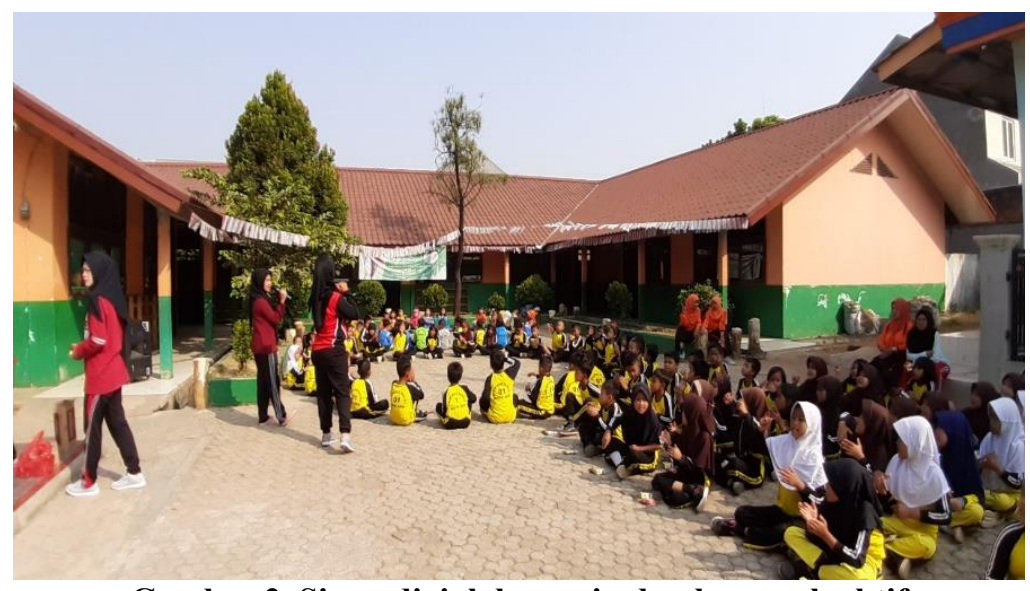

Gambar 2. Siswa diajak bermain dan bergerak aktif

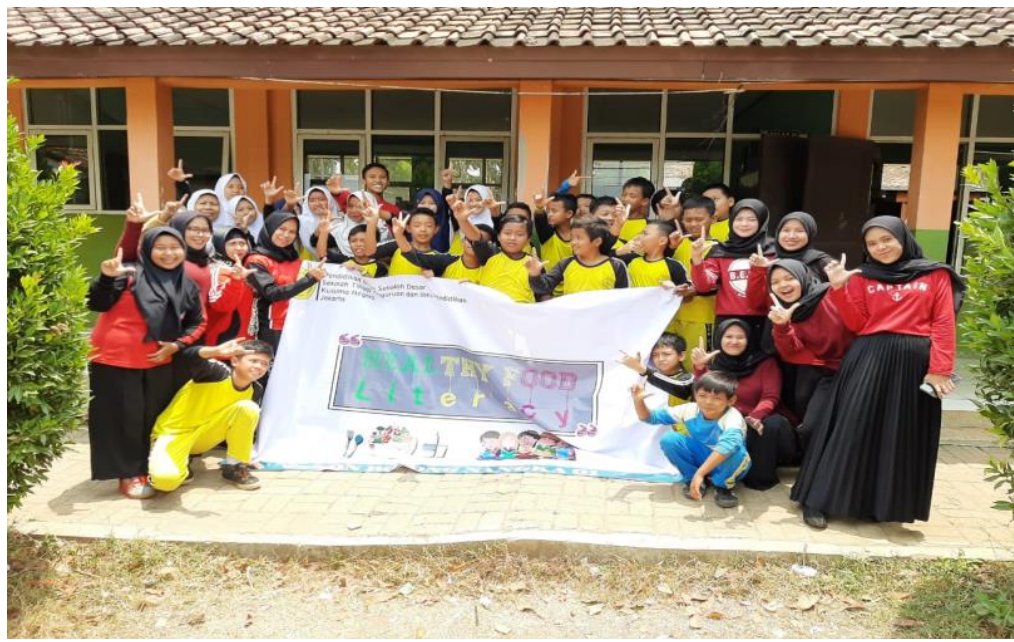

Gambar 3. Sesi foto Bersama

\section{DAFTAR PUSTAKA}

Aprilia, F. (2020). Makanan Sehat. Diakses pada 5 Januari 2020 dari https://www.halodoc.com/kesehatan/makanan-sehat

Arga Teriyan, et al. (2021). Strategi Bertahan di Masa Pandemi Covid-19. Jurnal Peradaban Masyarakat. 1(2). 29-32

Hasanah, U. (2019). Strategi Guru Dalam Meningkatkan Healthy Lifestyle Melalui Program Literasi Hidup Sehat. Jurnal Pendidikan Dasar, 10(2), 24-34.

Lova, Cynthia. (2019). 33 Murid SD di Depok Kena Hepatitis A, Dinkes Cek Jajanan di Sekolah. Diakses pada Januari 2020 dari https://megapolitan.kompas.com/read/2019/01/28/14144971/33-murid-sddi-depok-kena-hepatitis-a-dinkes-cek-jajanan-di-sekolah.

National Health and Medical Research Council. Australian Dietary Guidelines. Canberra: Australian Government; 2013.

Patty, A.M. (2008). Permainan Untuk Segala Usia. Jakarta: PT BPK. Gunung Mulia 